Article

\title{
Towards a Discourse-Based Understanding of Sustainability Education and Decision Making
}

\author{
Anke Meisert * and Florian Böttcher* \\ Department of Biology and Chemistry, University of Hildesheim, 31141 Hildesheim, Germany \\ * Correspondence: meisert@uni-hildesheim.de (A.M.); flboettcher@posteo.de (F.B.)
}

Received: 26 September 2019; Accepted: 18 October 2019; Published: 24 October 2019

\begin{abstract}
Based on the indeterminate character of the sustainability concept, a procedural and discursive understanding of sustainability decision making and corresponding approaches for education for sustainability (EFS) is proposed. A set of criteria for teaching strategies to promote sustainability decision making, taking into account the demands of deliberative democracy theory, are presented. These criteria (such as reason, complexity management, critical thinking, etc.) are used to argue for an educational approach that involves the development, justification, and weighting of arguments in combination with an instructional tool called Target-Mat. According to a consequent process orientation, structures for arguing or defining sustainability are not given as authorized standards. Suggestions from previous social discourse are only introduced as controversial pairings-for example, different definitions of sustainability. Examples of student decision-making processes are given to demonstrate the potential of the approach to encourage student reflection and cooperative negotiation that engenders a successive deepening of their argumentation.
\end{abstract}

Keywords: discourse orientation; decision making; sustainability education; instructional design

\section{Introduction}

The promotion of decision making and argumentation in socio-scientific issues is a well-established goal of science education [1,2], and therefore, a prominent element of scientific literacy $[3,4]$. Research into this has generally described students' problems with accounting for sufficiently relevant facts [5,6]; identifying and explicating underlying norms and values [1]; and weighting the relevance of multiple aspects and interests [7]. The field of SSI (socio-scientific issues) is greatly influenced by the challenges of new scientific developments such as stem cell therapy, genetic diagnostics, and stem cell research. However, managing SSI such as natural reserve or resource preservation has developed into part of environmental education with particular requirements for improving students' decision making [8] and its further development as education for sustainability (EFS).

EFS itself requires a set of multiple skills and competencies $[9,10]$, and is somewhat influenced by early approaches to environmental education [11], which are aimed at encouraging both decision making and action. For EFS, decision making has become relevant in order to enable students to "deal constructively with conflicting interests and objectives, [ ... ] in line with the action- and problem-oriented approach of "Umwelterziehung"" (i.e., environmental education) [11] (p. 234). This educational challenge has led to different approaches that can clearly be contrasted: a training of narrowly instructed decision-making strategies [12] versus a student-directed fostering of critical thinking [13] (a fundamentally different pedagogical approach stems from a critique of human's rationality and conclusions called nudging (see chapter 4)). Accordingly, approaches can be reflected critically upon with regard to their degree of instruction and resulting aspects such as the degree of transparency [14], connections to everyday knowledge [15], and meaningful learning [13]. 
Although some approaches offer applicable and systematic methods of tackling "factual and ethical complexity" [11] (p. 235), the question is raised as to whether or not narrowly defined skills and decision-making strategies are both appropriate in light of the societal discourse on sustainability and in agreement with educational goals beyond learning and practicing a predetermined set of skills. Kuhn takes a similar view of skill-based instructions, "regarding critical thinking and reasoning argument less as an individual skill and more as a social and cultural practice" [15] (p. 2). From these considerations arise two questions of the suitability of educational approaches to decision-making for sustainability: their suitability in terms of real social discourse, and their suitability in terms of reasonable educational goals.

The question of suitability between an instructional approach to decision making for sustainability and actual social discourse requires an analysis of the latter. However, social discourse on sustainability draws a vague and underdetermined picture rather than a precise one. Although sustainability is a very well-known concept that is used to reflect upon problems and conditions of current human life and those of future generations, the concept is seen as imprecise and to have a contingent reference to facts and values, because there are many different definitions of sustainability [16]. Some researchers have come to the conclusion that none of the definitions of sustainability analyzed could contain every relevant aspect of this concept.

It has to be discussed what serves as criteria to determine the necessary components of any such conceptualization. For example, Ciegis, Ramanauskiene, and Martinkus [17], resort to using the somewhat broad and very general conceptualization of the Brundtland report [18] after having analyzed hundreds of existing concepts of sustainability in the literature. They explain that "we tend to think that the most appropriate definition that best expresses the idea of sustainable development is provided in the report of the Brundtland commission, stating that sustainable development is the development that satisfies the needs of the current time period without jeopardizing the ability of future generations to satisfy their needs" [17] (p. 34).

As a consequence of the absence of a clear definition of the term sustainability, it is used by different factions who argue that their particular goals are in agreement with sustainable action. Therefore, it often serves as a purely rhetorical statement to claim one's goals as being in line with the concept. Using the concept in this way makes it adaptable to various contexts without entailing any relevant modification of everyday action [19] (p. 3). Vos describes this adaptive handling of the definition as follows: "There is less agreement as to what belongs in definitions of sustainability. Definitions may take one or another position along a range of dimensions, or may simply leave some dimensions out entirely [20] (p. 334). The problem of the concept of sustainability, which allows for such a broad application of the term, is its missing normative determination [21] (p. 21).

However, the problem is not one of not already having established a valid conceptualization. Dingler [22] and others have shown that it is not possible to recognize the global challenges that are to be faced and then to 'discover' an adequate concept of sustainability that would endure over time. Every content-based definition of sustainability is the result of a discursive procedure that is not finally concluded, because if and when new data is made available, new interests are integrated in the discourse, and problem-solving strategies might change. Which kind of development or non-development is sustainable can only be decided in the future. So, the definition problem is rooted in the future-oriented character of sustainability, as aptly formulated by Ramsey: "Definitions [of sustainability, added by the authors], can be meaningful (and therefore useful and important) only in relation to already given contexts of meaning [23] (p. 1076).

Both the lack of normative determination and the ongoing development of the sustainability concept do not offer a normative stabilized basis for decision-making and corresponding strategies. Rather, extensive negotiation processes are necessary [16], and which are also seen as a way to stabilize norms in the political understanding of this [24]. Therefore, a consequent procedural understanding of sustainability is necessary: "The lesson for sustainability is that we will not be able to define our way to clarity. Rather, we will have to rely on how we go about doing and performing 
sustainability" [23] (p. 1076). For example, this raises the question of suitable conditions for decision making for sustainability. Such an approach does not have the same problem of an insufficient definition as does a content-based conceptualization of sustainability. However, a process-oriented understanding of decision making for sustainability runs the risk of developing extremely complex and fixed strategies $[25,26]$ to overcome the complexity of the problems and the previously mentioned lack of normatively stabilized criteria.

However, instructing predetermined and narrowly defined decision strategies for sustainable solutions threatens to obscure the problem that, as of now, there are no reliable strategies to engage in the key issues of sustainability. Therefore, self-reflectivity and constant discursive critical review as well as contextual additivity should be inherent elements of any procedural understanding of sustainability. This provides a first answer to the above question of the suitability of educational approaches to reasonable goals. Approaches of deliberative democracy can offer ideas of how to structure discourse and decision making in order to come to conclusions in related domains while also preserving the necessary receptiveness toward modification. Therefore, students should be encouraged to realize that strategies of transformation toward decision making for sustainability (and sustainable behavior) can be either be developed or developed further. In addition, giving learners the impression that fully worked out and directly instructed and strategies would definitely lead to sustainable solutions has to be avoided.

This has further consequences for education, and requires the development of coherent instructional approaches that correspond to the process dimension of sustainability discourse. Instead of focusing on the teaching of abstract concepts of sustainability-which can only be adapted with difficulty-for decision making or for the promotion of a priori chosen decision-making strategies that risk being inadequately implemented and are not transparent [14], students have to learn how to organize discourse to reach suitable solutions. Bengtsson and Östman [27] state that the identification of education for sustainability as an empty signifier has the positive consequence of encouraging further discourse for greater clarification. The authors emphasize the need for the contingency of alternative theories: "Contrary to the critique put forward against education for sustainability, its instability, fuzziness, and internal contradictions should not [...] be judged to be an internal insufficiency of the concept or idea behind the concept, but instead could be seen to result out of the need to create equivalences among a number of specific and distinct discursive positions" [27] (p. 484). Therefore, a perspective change of sustainability helps to formulate its educational value as a procedural discursive approach and to understand the confusing situation of multiple and conflicting content-based conceptualizations.

Therefore, this paper first reflects on the potential of deliberative democracy for sustainable decision making in general and in educational contexts in particular. Second, the actual approach of nudging, which attempts to overcome limitations of human decision-making capacities, is discussed. Finally, the resulting ideas of deliberation and discourse in decision-making for sustainability are presented, which contain underlying criteria, instructional steps with concrete educational tools, and empirical examples for students' deliberations after discourse-related interventions.

\section{A Dialogical Understanding of Sustainability}

As previously mentioned, an exploration of the sustainability discourse shows a lack of consensus on a general definition of sustainability. Different perspectives of how to understand sustainability coexist and change over time, and concern both its descriptive and normative dimension.

Additionally, there is an interpretative gap between general definitions of sustainability and a concrete sustainable solution in a problem-solving task. To fill this gap, a dialogical negotiation process has to occur. Dingler [22] explains that sustainability is a contingent political concept based on social construction. Based on different contexts of discourse, different conceptualizations of sustainability are simultaneously legitimate [22] (p. 488). This refers to general definitions of sustainability as well as to concrete sustainable problem solving. Therefore, sustainability has the character of a "regulatory idea" 
that only serves as a "heuristic structure for reflection" [28] (p. 60). Consequently, a content-based understanding of the term is problematic, as the procedure of reflection is the key to understanding why a certain solution has been deemed to be sustainable in a problem-solving task. Ratner [16] (p. 51) also argues for an expansion from a content-based to a dialogical understanding of sustainability, and proposes a characterization of sustainability as a dialogue of values.

Therefore, when people are searching for the best available solution in a given context, based on dialogue, it can be asked what finally makes a solution sustainable, and what is the difference-if one exists-between a good and a sustainable solution [29]? According to Ratner, sustainability is a framework for taking a meta-perspective of determining and dealing with different or conflicting understandings of "good": "The sustainability concept is meaningful, therefore, not because it provides an encompassing solution to different notions of what is good, but for the way it brings such differences into a common field of dispute, dialogue, and potential agreement as the basis of collective action" [16] (p. 62).

However, the ongoing discourse on how to understand this concept is not a unique quality of sustainability. The definition of morally related terms such as sustainability, justice, and democracy is influenced by the current moral zeitgeist of the participants of discourse-that is, of a society. Each term refers to a loosely connected set of topics that have been part of discourses concerning this term. Sustainability itself has become legitimized, based on the central idea of resource conservation from which emerges the need for the transformation of economic value creation. A reflective use of resources becomes the elementary principle of societal transformation that is based on the analysis of current problems. Two questions then arise: how can resources be preserved, and how can any goals be strategically implemented?

Based on the lack of a normative determination of the concrete character of such changes, priorities of resource use and conservation and correspondingly of suitable transformation have to be determined in the decision-making phase and the phase of concrete implementation through this approach of discourse. As the need for discourse is often connected to questions of norm application, the need for discourse in this context is considerable, as the nature of norms themselves has to be sufficiently determined. It follows a higher level of a preliminary character of solutions in the context of sustainability when compared to other contexts, and therefore has an important educational value for the implementation of discourse-based approaches.

In Section 3, criteria from deliberative democracy are presented as a possible way to structure discourse in the problem solving of sustainability issues. Various aspects that are specific to the sustainability discourse are discussed.

\section{Structuring Discourse: Characteristics of Deliberative Democracy}

Theoreticians such as Habermas [30] and Apel [31] contributed important input to theories of deliberative democracy that emphasize an open and public evaluation of arguments in order to identify the best solution, which therefore depends on the participation of concerned citizens. Models of deliberative democracy [32-34] from political theory emphasize the importance of the inclusion of certain characteristics of discourse. In deliberation, participants refer to each other and each other's perspectives, preferences, and arguments in order to reach well-founded and transparent conclusions [35]. Different positions, new facts, their validity, and different value spheres have to be considered based on rational argumentation and reciprocity, and cannot simply be ignored to preserve an already established point of view.

"Deliberative democracy is therefore a way to address controversies through dialogue: when citizens or their representatives disagree morally, they should continue to reason together until they reach mutually acceptable decisions" [36] (p. 62). "The power of the best argument" is the guiding principle of the debate [37] (p. 59f.). Unlike decision making by voting, open deliberation can challenge the quality of arguments of participants. Chappell [37] concludes that this encourages people to uncover problems in their arguments, helps them revise them, become aware of new arguments, and 
strengthen the general critical reflection of the process. This only takes place when diverse viewpoints of different interest groups (or representatives of such groups) are included in the process. Therefore, deliberation concerns values of participants, but as it is not always clear which concrete interests or arguments are connected to abstract values, these have to be made concrete during deliberation in order to make interests and arguments available for negotiation.

Referring to Cohen [33], Chappell summarizes key features as background conditions for deliberative democracy, such as the process relying on a free and independent association for deliberation of equals, no necessary commitment to any belief structure, a transparent relation between the process and the outcome, and the recognition of participants as legitimate deliberators.

Having given these conditions as the basis for deliberation, the procedure itself is characterized by the following aspects [37] (p. 25):

"Freedom. Members of a deliberative democracy are bound only by the results of their own deliberation, and the fact that decisions are arrived at through deliberation is a sufficient reason to comply with them.

Reason. The results of deliberation depend only on the reasons members of the group present for making, defending or opposing a proposal.

Equality. Members of a deliberative democracy are both formally and substantively equal.

Consensus. The aim of ideal deliberation is to arrive at a consensus. In the absence of a consensus, decisions may be made through voting".

The goal of deliberation is ideally a rational consensus that is acceptable to everyone concerned because argumentation and plausible reasons for positions have been presented [36] (p. 62). The primarily focus of deliberative democracy is not on the moment of decision making, that is, in developing rules for an aggregation of preferences and of collecting votes [37] (p. 97). Deliberation has priority [35] (p. 138) as "the guiding idea of democracy" [38] (p. 76), as it focuses on the process on how opinions are challenged, changed, or modified through dialogue before a negotiated decision is reached, sometimes using the necessary step of voting.

Concerning these aspects, decision-making strategies based on rational choice, which are also embedded in frameworks of decision making for sustainability [11], are limited because they have to be seen as opposed to real deliberative processes aiming at striving for consensus [37] (p. 52). The problem is that the goal is primarily oriented toward an acceptance of fixed individual preferences, instead of focusing on communication and consensus building (including a possible preference change [37] (p. 54). Deliberative decision making would seek to find a consensus on an available option. Participating in deliberation can make reasons for different viewpoints transparent and allow reflected preference change [36] (p. 61).

If the process becomes transparent, preference transformation (as a necessary process of consensus building) can be understood [37] (p. 41). The advantage is that deliberative problem-solvers become familiar with the procedural features, and therefore learn to interpret changes of preferences or beliefs as possible parts of the deliberative procedure. From a meta-perspective, they could understand how this is a necessary part of any deliberation, and can accept changes of preferences because they further accept the general process. A different possibility is that consensus on the result is found, but the process itself is questioned and modified. This demonstrates that sustainability is a transformational process at various levels.

Arguing about the appropriate principles of deliberative decision making is necessary in order to make the outcomes understandable and acceptable. It helps to clarify the differences between good and legitimate decisions. Even if experts find a good solution to a problem task, their decision only becomes legitimate when "all reasonable people can agree on their expertise" [37] (p. 60) and, for example, a democratic process is involved. Augmented legitimacy might then enhance the efficiency and final implementation of decisions, as concerned parties are already involved in the process [36] (p. 64). However, the quality of the decision might suffer from the point of view of experts. Aspects such as 
legitimacy and quality are only part of decision making when the decision making includes various discourse-based aspects. Either the process's legitimacy is enhanced through the participation of stakeholders, and its quality is enhanced by the participation of experts, or the concrete structure of a decision-making process is legitimized a priori, such as for example through a democratic process and reflection. This is related to the importance of meta-cognition as a central competence in critical thinking [39] when participating in such discourses.

Focusing on theories of deliberative democracy for sustainable decision making might not be purely procedural, because procedural and substantive principles are relevant for deliberation - that is, to argue for the legitimacy of procedural criteria. Therefore, it is important to highlight their general preliminary character: "Both procedural and substantive principles are systematically open to revision in an ongoing process of moral and political deliberation" [40] (p. 154).

It follows that even if criteria for the quality of the deliberative process such as free and unconstrained discussion and a free access to all available and relevant arguments [41] (p. 186) can be discussed, there is no meta-position to decide once and for all a priori if the normative neutrality of the deliberation has been respected. Only participants in the process of decision making can answer the question as to whether or not every relevant argument has been taken into account [41]. Consequently, the educational opportunity to strengthen the participants' responsibility not only for the results, but also for the process itself, follows.

Nevertheless, some arguments for the quality of discourses structured in this way can be given, which are the result of this transparent and self-reflecting framework. Chappell emphasizes the quality of the outcomes, and also refers to the characteristics of the process itself in order to legitimize it: "Procedural or intrinsic justifications appeal to the values inherent in the process itself, such as equality, inclusion or self-determination" [37] (p. 28). Placing the quality of arguments at the heart of democratic deliberation increases the probability that the solutions found are more resistant to criticism and ensure social adherence to the decisions made [37] (p. 29). In terms of sustainability issues, this framework can help to manage the factual and normative complexity of problem-solving tasks.

The insight into deficiencies of solutions emerges from a historical perspective of past decision making. According to the concept of bounded rationality, human cognitive resources are limited and can lead to suboptimal decision making when results are reassessed. Recently, it has been discussed as to how far nudges, as influencers of decision making, should be considered as a legitimate instrument to ameliorate the quality of decision-making discourse and its outcome.

Section 4 discusses in how far and in which way education for sustainability has to take these considerations into account in order to encourage a learning environment that allows learners to participate in discursive decision making on sustainability issues.

\section{Considering the Limits of Rationality in Discourse and the Role of Nudging}

In the context of a discourse-based approach, two problems can be addressed. Firstly, the gap between decision making and any following concrete actions is known to limit the effects of sustainability discourse in education. Furthermore, the quality of decision making is substantially influenced by human cognitive capacities. This aspect is addressed in Section 4 .

The limits of human rationality have to be taken into account to estimate the possible quality of the resulting decision. In addition to having promising capabilities, human decision making is also characterized by bounded rationality. Cognitive resources are limited, and decisions are influenced by biases that result in suboptimal choices through failures of reasoning. Such failures can be made transparent by relating interests of decision makers and the results of decision-making processes: "It is therefore assumed that individuals inherently prefer to improve their choices" [42] (p. 252).

In recent years, the idea of nudging, merely as a tool of policy making, came into focus in order to make people avoid biases and improve the quality of their decisions. Sunstein [43] (p. 585) describes 10 important nudges: 1 . default rules; 2 . simplifications; 3 . use of social norms; 4 . increase in ease and convenience; 5 . disclosure; 6 . warnings, graphic or otherwise; 7. pre-commitment strategies; 
8. reminders; 9. eliciting implementation intentions; and 10. informing people of the nature and consequences of their own past choices. However, such strategies are only examples from empirically examined elements of the choice architecture that usually underlies decision-making processes.

In the context of sustainability education, two perspectives on nudging have to be taken into account. Firstly, is has to be discussed if and how nudging can be part of the learning environment in order to improve students' decision making on sustainability problems. Secondly, students can discuss if and how they themselves would like to implement nudges in order to make people choose or behave in a more sustainable way. To address these concerns, nudging is now explained in more detail.

Referring to the dual process theory of automatic and intuitive versus reflective thinking, Hansen and Jespersen differentiate between the types of nudges directed at each of these systems:

"Both types of nudges aim at influencing automatic modes of thinking. But while type 2 nudges are aimed at influencing the attention and premises of - and hence the behavior anchored in-reflective thinking (i.e., choices), via influencing the automatic system, type 1 nudges are aimed at influencing the behavior maintained by automatic thinking, or consequences thereof without involving reflective thinking" [44] (p. 14).

Additionally, they offer the epistemic dimension of transparency to differentiate between transparent and non-transparent nudges.

This differentiation is also relevant for educational contexts, as it helps to clarify whether or not manipulation is taking place. Transparent nudges can be reflectively integrated in the process of decision-making, whereas this is not possible for non-transparent ones [44] (p. 19).

Table 1 shows the four types of nudges that result. Transparent type 2 nudges influence people toward reflective decision-making: "Citizens are nudged to consider choices without the use of manipulative measures usually because decision-making itself is regarded as valuable" [44] (p. 24). Transparent type 1 nudges influence people's behavior, not their choices, but they are, in principal, transparent and can be discussed or ignored. Non-transparent type 1 nudges manipulate people's behavior, as they are not recognized. Non-transparent type 2 nudges manipulate people's choices.

Table 1. Types of nudges (taken from to Hansen and Jespersen [44] (p. 23).

\begin{tabular}{|c|c|c|}
\hline & Transparent & Non-Transparent \\
\hline System 2 thinking & A. Transparent facilitation of consistent choice & C. Non-transparent manipulation of choice \\
\hline System 1 thinking & $\begin{array}{l}\text { B. Transparent influence (technical } \\
\text { manipulation) of behavior) }\end{array}$ & D. Non-transparent manipulation of behavior \\
\hline
\end{tabular}

Therefore, as previously discussed, a discourse-based approach for sustainability education is proposed, as no final answer of what sustainability is can be presented to the learner (or to anyone else). To find an adequate conceptualization, one has to be enabled to participate in corresponding discourse and problem solving in order to negotiate and constitute the necessary guiding principles of discourse and to apply them in a chosen context. This is why non-transparent nudging cannot be part of sustainability education, and cannot be part of the discourse itself, that is, under the pretext of improving the decision making. Otherwise, one would create what Lodge and Wegrich call "the rationality paradox" by proclaiming an objective and superior rational instance that could decide if decisions have to be corrected by nudging: "At the heart of nudge is a basic paradox: it assumes bounded rationality, but offers a comprehensive vision of rationality to address problems caused by rationality" [42] (p. 253).

For example, this raises the question of how to control nudging activities if this manipulation is in the interest of those manipulated, and not of those manipulating. This question becomes more crucial if the manipulation is simply a result of biases (e.g., over-optimism or power-blindness) influencing the nudger [44] (p. 11). Lodge and Wegrich [42] explain that non-transparent nudges cannot be a solution 
for the limits of rationality, and they equally cannot be a solution for the perceived limits of the quality of sustainability decision making, as this would create a comparable paradox.

Even when considering that teachers have a special role as authorities in qualifying certain answers as correct or incorrect, this does not apply to the same extent to the context of decision making and moral judgment when students refer to their own interests. These considerations are supported by empirical studies that have investigated if decisional enhancement via overt or covert decision making is more acceptable to the decision makers. Felsen, Castelo, and Reiner [45] found that, in general, overt influences are more acceptable.

In particular, non-transparent nudges that influence reflective decision-making also have to be considered as problematic in educational contexts as the wrong impression of independent decisions is created: "Assuming that individual reflected preferences made in accordance with the self-images of citizens constitute the core of autonomous decision-making, as judged by the norms of democracy, as well as public opinion, non-transparent type 2 nudges constitute the most controversial type of nudges, because citizens are used as mere tools rather than treated as ends" [44] (p. 26). As the influence is non-transparent but based on type 2 thinking, even the responsibility is ascribed to the manipulated citizens as "official" decision-makers. Therefore, Hansen and Jespersen [44] find it difficult to see any use for such nudges in democratic societies, and this includes educational contexts. This very much calls into question existing models of sustainability education that offer complex decision-making strategies to learners that are only partly or not at all transparent in their effects on the decision-making process. If the features of the decision-making strategy are too complex to be understood or simply remain non-reflected, and therefore the relation between interests and the resulting decision remains obscure, this raises the previously mentioned question of manipulation. It follows that the discourse of sustainability problems can be facilitated through an appropriate learning environment that allows for the exchange of arguments and helps to make problems of bounded rationality (i.e., limited heuristics, biases, intuitions, and emotions) transparent to the participants of the discourse in a way that they can be part of the discussion, reflected upon, and discarded if participants decide to do so.

Transparent nudges-that is, in the form of information from historical sustainability discourse - can in the same way be important instruments to improve the quality of the decision-making process. In this way, questions of discourse and decision quality are considered when designing an appropriate classroom setting. The challenge is to transform general criteria for adequate deliberation on sustainability issues (i.e., equality of participants, orientation toward reason and arguments, freedom, consensus as a goal, inclusion of participants and opinions, etc.) into an interesting, motivating, and manageable learning environment. This could be done to help learners understand the procedural characteristics of sustainability (see Section 5 for an example).

\section{From General Criteria of Deliberation to an Exemplary Instructional Design for Sustainability Decision Making}

The previous analysis argues for a strict discourse orientation of decision making on sustainable problems. This discourse requires a consistent process-oriented attempt, which must be differentiated from approaches that aim at narrowly defined competencies or competencies through task-based decision support [46] or training [47]. Approaches that offer a set of elaborate operations (e.g., identifying criteria, weighting these criteria as well as case-related options and calculating the best one, see [12]) try to secure the outcome quality of the decisions and establish these operations as applicable competences or skills.

These fixed operations are guiding the processes, but on the other hand, they limit the decision-making process as well as the considered concepts, facts, and opinions. Operations such as identifying criteria and weighting them by numbers are fixed; therefore, the opportunities for student-directed choices for other strategies or key concepts such as deeply reasoning arguments or values are limited. This limitation conflicts with the idea of the participants' freedom in deliberative 
democracy approaches [48]. It also runs the risk that aspects and processes experienced as relevant will not be at the center of the decision-making process [14].

In addition, opening up to student-directed decision-making and student-selected arguments is of particular importance for sustainability education, as it requires taking into account the ideas and arguments of those concerned as an essential prerequisite for (preliminary) sustainable decisions. The aim of this promotion of willingness and ability to take into account the interests and perspectives of others is to overcome one of the most serious errors in unsustainable decisions at local and global levels, which is ignoring relevant interests.

This student-directed approach matches with the central ideas on argumentation and critical thinking discussed by Kuhn, who also demarcates her own ideas from those who emphasize that "explicit instruction [is] the most powerful tool in developing critical thinking" [15] (p. 123). Furthermore, she stresses the importance of "dialogic argumentation as a productive vehicle for developing both individual and dialogic argumentative competencies" and the corresponding potential to take "everyday social practice of argumentation as a starting point and pathway for development of individual argumentative thinking" [15] (p. 123).

Both the focus on a dialogical setting and the connection to everyday practices require careful instruction with a high level of student-directed processes, which can be fulfilled by a discourse-based approach. The connection to everyday strategies and the dialogical setting guarantee that the learners will be encouraged by the experiences, solutions, and competences gained in this way to face the challenges of future sustainability decisions.

Therefore, a consistent implementation of the ideas of deliberative democracy and critical thinking for decision making on sustainability problems must depart from a narrow commitment to procedures and consistently orient the instructional design to the promotion of a participatory discourse, because "deliberation involves more than formal mechanism of decision making" [49] (p. 121). Thus, discourse is not the means to an end, but is itself the goal in the sense of experiencing negotiation processes and their potential to generate mutually accepted solutions. In the general spirit of Kuhn's understanding of argumentation, and its fitting to the discourse approach, decision making on sustainability issues can be essentially characterized "as a social practice, rather than a strictly individual competency" [15] (p. 121). Compared to general argumentation, the social dimension of decision making on sustainable issues becomes even more important because of the above-mentioned need for negotiation processes in terms of multiple interests, values, and less well-established norms.

A full discourse orientation means that the decision processes and discussed concepts are negotiable (see Section 2). This is promising, because the learners become, to a certain degree, responsible participants in real social discourses. However, as an educational approach this is not to be understood as a non-structured learning environment. Rather, all process constituent operations and concepts that are relevant to argumentation and decision making do not invariably serve externally authorized standards, but support discourse on the concrete and the metacognitive level. Therefore, instructional elements such as content- or process-related information have to be understood as proposals, and have to be selected with regard to their accessibility to and modifiability by the students. In order to credibly implement such aspects as proposals in the school context for the learners, these instructional elements should be designed as alternative contrast sets as much as possible. This indicates that consistent discourse orientation in the context of EFS is associated with a variety of questions on how to construct the instructional setting, which is discussed in more detail in the following subsection.

\subsection{Criteria for Educational Approaches to Foster Sustainability Discourse in the Classroom}

Before concrete teaching strategies are reflected upon, it makes sense to review general discourse standards in terms of deliberative democracy, regarding their potential for sustainability discourse in the classroom. For this purpose, criteria of the debate on deliberative democracy are now reflected upon and expanded with regard to the specific requirements of educational contexts and sustainable issues. 
Equality (1) and reason (2) are two of Cohen's first introduced key features of deliberative discourse [48], and were later supported by Chappell [37]. They represent basic requirements that demand a cooperative and argumentative debate between equal participants. Cohen's other feature, consensus, is also compatible with Chappell's approach, who emphasizes the goal-oriented nature of deliberative discourses by characterizing them as a problem-solving process. Therefore, consensus (3) constitutes a third criterion, which basically initiates the decision-making process. Additionally, consensus as a learning goal fulfills a basic instructional function, as transparent objectives are key factors of appropriate learning environments [50]. Open discursive processes in educational contexts often lead to inadequate deliberations [6,7], which are partially reached through unreflected voting; therefore, the consensus goal forms an important marker for the discourse quality with regard to the acceptance of the results.

The fourth core feature of deliberative discourse, characterized by Cohen [48], is freedom (4). This criterion is of special interest in educational contexts, as students are often guided implicitly by teacher or institutional expectations. However, freedom is a precondition of authentic argumentation and of real experienced conflicts of interests, and is closely related to the demand of autonomy [49] (p. 115). Furthermore, freedom matches the instructional aim of student-directed decision making, and is classified as a central precondition of meaningful decision making in the classroom [14].

Therefore, the criterion for freedom has to be understood in a broad sense, which includes an argumentative (i.e., freedom to mention own arguments) and procedural as well as a conceptual (i.e., free for diverse and controversial discourse processes and concepts) dimension. As possible discourse behavior, learners can also decide not to participate in the discourse, which leads to a loss of their participation. This is related to the need to allow any kind of decision making, and can enable an informative experience of the competing nature of freedom and participation, in addition to all the disadvantages that this might entail.

Beyond the idea of freedom and equality, Chappell cites inclusion (5) as a further feature of deliberative democracy, referring to the inclusion of both people and arguments [37] (p. 80). The inclusion of people is limited and fixed in schools; therefore, this criterion is important in two ways. Firstly, students involved in the discourse have to be encouraged and fostered to participate in the debate, as the discourse can only succeed if diverse and potentially controversial participants become authentically involved (i.e., inclusion of people). Against the background of this criterion, didactic approaches must aim at actively involving students, who have different communicative and argumentative competencies, in the discourse.

This then leads to the importance of an inclusion of arguments: as the participation of people and their corresponding diversity of interests are necessarily limited by the school environment, the inclusion of relevant arguments is an important factor to ensure decision-making processes that have realistic references to real-world problems. This inclusion of arguments relates in particular to sustainability, because the consideration of marginal or non-mainstream perspectives, arguments, and interests is one of the core problems of the sustainability discourse. The criterion-inclusion of arguments-leads to the requirement that arguments that are relevant for the topic but unknown to the group should be introduced in the discourse. This also considers the previously mentioned importance of knowing the results, successes, or errors of historical sustainability decision making, and of offering them as an information background.

While most of the previous criteria relate to general discourse activities, another challenge arises in terms of sustainability, which results from the factual and normative complexity (i.e., multiplicity and interconnectedness of relevant aspects) of its problems [11]. This complexity carries particular risks of failure, especially for novices, as they often prefer cut-off strategies instead of trade-offs [12]. If they use trade-offs in less complex contexts, they fail in the weighting them [7]. This lack of compensatory decision-making strategies prevents an awareness of facts or interests that are potentially relevant. This does not mean that a final cut-off decision is not legitimate, but rather that complexity itself determining the strategy instead of reasoning should be avoided. Once again, it has to be clarified 
that judging the appropriateness of any weighting strategy can itself be part of discourse- that is, in revealing the disadvantages of cut-off strategies. Therefore, the appropriateness of approaches toward fostering sustainable discourse must also be judged in the light of their complexity management potential (6).

Three further criteria are particularly related to an educational context, which is characterized by a lack of expertise of the participants and the formal educational characteristics of the setting. The latter obviously limits the key feature of freedom, which emphasizes the demand for student-directed processes as much as is possible. As self-direction requires the participation of responsible and reflective students, the initiating of critical reflection (7) of their own decision processes, with all its attendant aspects, is an important criterion for instructional approaches of sustainable discourse. This criterion is additionally supported by the previously mentioned relevance of critical thinking for argumentation and decision-making in general. Furthermore, critical reflection is an indispensable chance to transform any kind of instructional guiding (or nudging, see Section 4) in a transparent form.

Despite the possibility of allowing learners to reflect on the decision processes and results critically at any moment, instructional strategies have to be analyzed very critically with regard to their implicit prioritizations and preliminary decisions, as previously discussed. Therefore, teaching strategies must be balanced between the fostering of critical thinking and managing complexity on the one hand, and normative neutrality (8) on the other. The degree and character of corresponding instruction is a central challenge demanding a "principled path between intrusion and laissez-faire" [49] (p. 117). This demand for normative neutrality also corresponds to the discourse on sustainability with an unstable normative basis, which requires a "dialogue of values" [16] (see Section 1).

A very critical demand on educational approaches for decision making with political relevance is the last criterion of applicability (9). The educational context requires many adaptations that take into account the low level of expertise and the obligatory and simulative character of the discourse situation. This has partly led to artificial learning environments such as role playing, with the goal of creating authentic scenarios [51]. However, the authenticity of this type of learning situation is questionable. Therefore, the activity of role playing is different from authentic reasoning, "as students may have to argue a position which they have not thought through and which may be very biased in a particular direction" [52] (p. 67). In terms of applicability to actual democratic debates, a pedagogical approach must allow students to communicate their own arguments and to experience real controversy.

\subsection{Initiating Sustainability Discourse by 'Developing, Justifying, and Weighting Arguments' with the 'Target-Mat'}

In addition to aspects such as the degree of instruction and ways to make students interact, educational approaches to decision making in science education are primarily based on strategies that are used to structure the decision process. Two structural dimensions can be distinguished: On the one hand, the learning progression establishes a sequence of operations that constitutes the subsequent process structure of the decision making. On the other hand, for the single steps, the problem area is divided into manageable packages (i.e., complexity structure), which can be cognitively processed by the students. Both types of structuring have a great impact on the kind of discourse initiated, and have to be justified for any educational approach on sustainability discourse in the science classroom before making concrete further instructional decisions.

With regard to the partition structure, different educational approaches favor criteria as instrumental units, by which the decision-making process can be realized [2,12]. The collecting of relevant criteria encourages the consideration of multiple aspects with the potential of reducing the tendency of non-compensatory weighting [7]. However, this focus on criteria structurally reduces the students' consideration of aspects that can be referred to by single words that have broad normative implications. Consequently, these criteria are usually culturally established and meaningful concepts such as health and freedom. Values and interests are less established in a society, and consequently not represented by frequently used words; therefore, there are fewer opportunities for them to be considered in a criteria-based decision structure [16]. 
Moreover, these abstract criteria are usually applied simultaneously to different options, easily leading to conceptual blurring. For example, applying a single criterion such as ecosystem quality to different options can result in different interpretations of the criterion-for example, for the quality of human welfare or for the quality of biological diversity. This might cause problems in the decision-making process. As a further argument against the focus on criteria, students are not familiar with solving problems using such criteria-based and formalized procedures [7]. However, great differences in their common strategies reduce the students' autonomy (see above) as well as the applicability in their everyday contexts.

In addition, many studies have shown that students are already content with marginally relevant and barely justified arguments [2,6]. Linguistically dense units tend to blur the important integration of factual and normative aspects of arguments; therefore, their use often results in a lack of normative transparency [6].

Regarding their connectivity to primary knowledge and everyday strategies as well as the accessible character and openness for more or less established considerations, arguments offer a more appropriate unit of reflection with regard to the partition structure. Containing both a statement and justifying reasons, arguments represent enriched units upon which reasonable negotiation processes can be based. They offer a separation into manageable packages for the decision-making process. Furthermore, arguments refer directly to one of the options with the potential of specifying the underlying reasons and avoiding conceptual inaccuracy.

Using arguments as the partition structure, the approach of "Developing, Justifying, and Weighting Arguments", first described by Meisert [53] and further developed by Böttcher, Hackmann and Meisert [54] offers a process structure that is aimed at activation of the students' own argumentations, reflections on their arguments' justifications, and their compensatory weighting as a particular requisite of multifaceted problems. Therefore, this argument-based approach favors a six-step process, which starts with a development of the problem context, followed by the development, justification, and weighting of arguments, and then a final decision (see Table 2). After these five steps have been taken, a reflection on possible consequences (individually or socially) may follow.

Table 2. Process structure of the developing, justifying, and weighting argument approach (see [52]) and its potential for decision making on problems typically associated with sustainability concepts. SSI: socio-scientific issues.

\begin{tabular}{|c|c|c|}
\hline Decision Steps & Instructional Function & $\begin{array}{l}\text { Potential for Decision Making on Problems Typically } \\
\text { Associated with Sustainability Concepts in the } \\
\text { Public Discourse }\end{array}$ \\
\hline $\begin{array}{l}\text { exploring an } \\
\text { exemplary SSI }\end{array}$ & $\begin{array}{l}\text { understanding the central conflict and } \\
\text { contextual conditions }\end{array}$ & $\begin{array}{l}\text { to recognize the diversity of problems/conflicts in a } \\
\text { context and to negotiate the central problem to } \\
\text { be solved }\end{array}$ \\
\hline developing arguments & $\begin{array}{l}\text { collecting possible arguments and first } \\
\text { understanding of relevant facts and norms }\end{array}$ & $\begin{array}{l}\text { to include the diversity of arguments originating from } \\
\text { the participants and/or the public discourse }\end{array}$ \\
\hline justifying arguments & $\begin{array}{l}\text { reflecting upon the argumentative resources by } \\
\text { explaining their factual and normative } \\
\text { foundations as well as their validity }\end{array}$ & $\begin{array}{l}\text { to manage factual complexity and uncertainty in order } \\
\text { to make norms explicit }\end{array}$ \\
\hline weighting arguments & specifying the arguments' relevance & $\begin{array}{l}\text { to offer a possible strategy of compensatory weighting } \\
\text { in order to overcome a multitude of problems }\end{array}$ \\
\hline final decision & finalizing the decision process & $\begin{array}{l}\text { to remain consensus and solution-oriented despite the } \\
\text { diverse challenges }\end{array}$ \\
\hline $\begin{array}{l}\text { reflecting upon } \\
\text { consequences of } \\
\text { the decision }\end{array}$ & $\begin{array}{l}\text { deducing possible consequences for the } \\
\text { students' behavior }\end{array}$ & $\begin{array}{l}\text { to create a realistic and everyday awareness of the } \\
\text { far-reaching consequences of decisions with } \\
\text { transformative dimensions }\end{array}$ \\
\hline $\begin{array}{l}\text { reflecting upon the } \\
\text { decision-making steps } \\
\text { and results }\end{array}$ & $\begin{array}{l}\text { - evaluating the process, the final result, } \\
\text { and its consequences for further } \\
\text { decision making } \\
\text { rerun the process, if necessary, with } \\
\text { integrated modifications } \\
\text { (circular process) }\end{array}$ & $\begin{array}{l}\text { to raise the awareness of the strategic challenges of } \\
\text { decision making }\end{array}$ \\
\hline
\end{tabular}


Following the perception of students' great potential for argumentation in suitable environments $[15,54]$, the six-step process structure is designed to create argumentation opportunities arising from group-based negotiations on the relevance and/or weighting of the single arguments. To substantiate these negotiations of factual and normative deliberations, it is recommended that the previous step includes reflections upon the arguments' justifications. This process structure serves to overcome deficits of inadequate factual and normative deliberations as well as the previously referred to undifferentiated cut-off strategies of decision-making. Due to its core characteristics such as being student-centered and meta-reflective as well as process-transparent and adaptable, this approach offers a considerable potential to realize the previously discussed process dimension of the sustainability discourse.

This approach is now instructionally concretized in conjunction with the corresponding visualization tool 'Target-Mat' [55] (see Figure 1 with described application), as it plays a central, facilitating role for the discursive and student-centered potential of the approach. Simultaneously, the 9 criteria previously presented are used to reflect the appropriateness of the discourse approach in terms of its strengths and weaknesses.

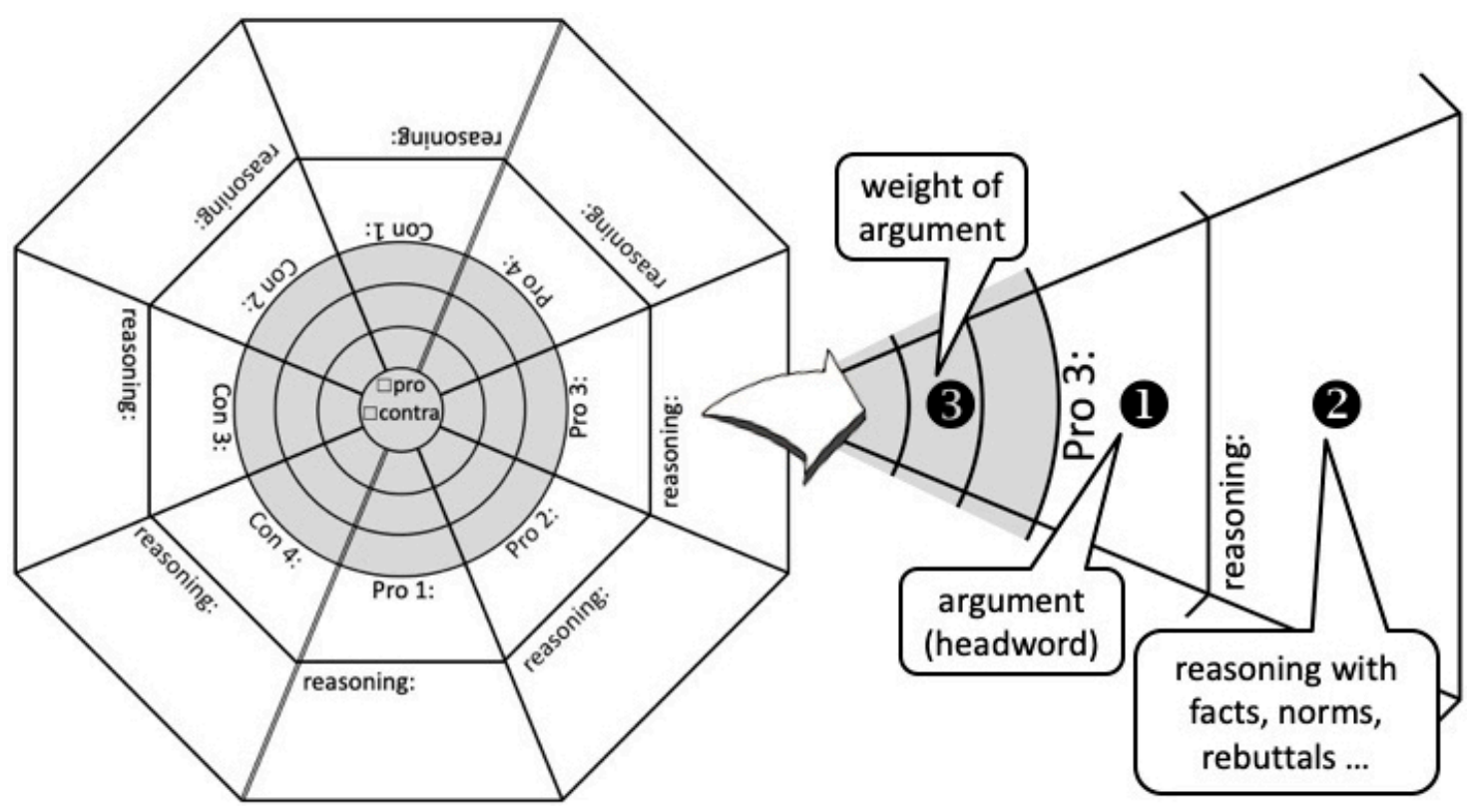

Figure 1. Structure of a Target-Mat, related steps (1-3), and their function (adapted from [55]).

As previously described, the argument-based approach of 'developing, justifying and weighting arguments' then structures the diversity of relevant aspects into problem units by assigning them to arguments and by using these arguments as weighting units [52]. By merging partial aspects to form arguments, manageable reflection units emerge, which offer scope for considerable justifications and corresponding controversies in this process (i.e., reason). At the same time, the unit 'argument' is connected to everyday knowledge and serves as a comparatively non-specific circumstance (i.e., neutrality) for the collection of aspects relevant to the argumentation. The collection and further reflection of several arguments require a type of restructuring aid. This function can be fulfilled by the Target-Mat, which has been developed as a synthesis of the educational tools, target, and placemat [55], offering opportunities for a visually structured documentation of arguments' explanations and justifications and their relevance in the form of a weighting.

The discursive quality is created through the step that each participant (i.e., equality) can add strengthening and debilitating aspects (i.e., freedom) to each argument by using the Target-Mat. This collection of the arguments' explanations and justifications subsequently serves as the basis for the following negotiation processes in groups (i.e., consensus), which initially relate to the weighting 
of each argument. By focusing on arguments as small weighting units, an overall decision is preceded by small negotiation processes. These steps subdivide the complexity of the aspects to be negotiated, thus providing the opportunity for focused reasoning. Additionally, the change from individual clarification to common negotiation in small groups of students, as well as verbal and written statements, also encourages a high level of participation (i.e., equality, inclusion) because, in oral interaction only, individual participants easily dominate the discourse [6].

By following these partial negotiation processes with many detailed explanations, an overall negotiation can be entered. The Target-Mat, with the previous clarifications and weightings of the arguments, then provides a transparent basis for reaching the final consensus. On the one hand, this not only represents an important strategy toward complexity reduction, but also provides a basis for a critical reflection of the process or individual process results (i.e., reflection). This reflection is not to be understood as a final solution, but rather as an accompanying element of the process. In this way, the process can be reflected upon and adapted to different phases by the learners. This could refer to additional factual information, more sound argumentation, or an adaptation of the Target-Mat itself (more levels of weighing, more segments for arguments, etc.), starting the process for student-directed decisions about the strategy (i.e., freedom).

The previous remarks on the presented discourse approach, in combination with the Target-Mat, have most importantly the character of a structuring instrument with a low degree of instruction. However, it is worthwhile discussing this approach again with respect to other instruction strategies. Discourses without any further structuring aids often contain deficient arguments [51], although they already fulfill the expectation of a dialogical or cooperative character of argumentation $[15,56]$. The necessity of encouraging the students' discourse is also discussed by Michaelis, $\mathrm{O}^{\prime} \mathrm{Connor}$, and Resnick with regard to scientific argumentation, emphasizing "the central role of particular forms and norms of discourse" [57] (p. 284). However, this type of teachers' guidance obviously involves predetermined standards that infringe upon the students' discourse. This strategy of adhering to authorized standards (e.g., by teachers' verbal stimulus or in some other manner) is not compatible with the previously mentioned discourse approach. Although the Target-Mat in the here-presented approach represents a particular structure or form for the negotiation process, it firstly offers a high potential for transparency because of its obvious and visualized structure, and secondly is itself an object of critical reflection. Even if there is no teaching without nudging, the instructional tools of nudging have to be shaped for transparency (among other goals). Regarding the high normativity of sustainability discourse and the students' sensible awareness of teacher signals, instructional tools, and strategies, it seems suitable to allow the teachers to act in the background (to avoid unconscious and non-transparent nudging, see Section 4).

\subsection{Introducing Models and Concepts in a Classroom Sustainability Discourse}

The previous assertions have shown a strategy for the initiation of discourse activities that can be largely controlled by the learners. However, the criteria of reason and inclusion require that any classroom discourse have to consider the central perspectives and arguments of the actual sustainability discourse. However, any selection of the multiple facts, concepts, or perspectives runs the risk of biasing the discourse (in the sense of non-transparent nudging, see Section 4). This is compounded by the fact that many of the relevant norms in the context of sustainability are not well established, and many of the relevant facts are unsubstantiated. This increases the susceptibility of the discourse to manipulative influences. Therefore, not only the decision-making strategy, but also the introduction of facts, concepts, and models has to be reflected in the light of its normative neutrality.

One strategy to avoid manipulative influences is to present the introduced elements as contrast sets by always offering two controversial perspectives. By doing so, the learners are required to critically think about the introduced elements. Furthermore, they experience the controversial and developing character of the discourse as being representative of the sustainability dialogue in general. At the same 
time, this contrast-set strategy does not incapacitate learners with implicit norms, but rather activates their critical thinking through positioning in light of the controversial points of view.

Controversial models of sustainability (see Section 2) or different concepts of justice can, for example, activate learners' critical thinking. Additionally, this clarifies the general negotiable nature of the problems, and makes the need for discourse transparent. Even different models of argumentation (e.g., practical syllogism versus Toulmin model of arguments; deontological versus consequentialist argumentation; biocentric versus anthropocentric arguments) can then be useful, but only when they are offered as alternatives and not as single norms without alternatives. The criteria for the selection of the alternative concepts is their use in current social discourse on the problem area selected in each case.

\subsection{Examples Demonstrate the Potential of the Semi-Structured Negotiation Processes}

In the following, examples are given of the developmental character of negotiation processes, using the Target-Mat. Two brief insights into a corresponding intervention study are given, which include the written justification and weighting as well as an extract of an oral negotiation process. The examples are taken from an intervention study (eighth grade students, $\mathrm{N}=146$ ) that focuses on the construction of a new amusement park in a forest area which—among the area's other functions-serves as a habitat for wildcats (see [58]). The data for the analysis of the written justification and weighting (Table 3) were directly transferred from the students' Target-Mat working sheets. The reasoning is interpreted in terms of activated argumentative resources such as facts or norms [58] and changings comparing the individual reasoning before and after the group negotiation. The analysis of the oral group discussion (Table 4) takes place in two steps: First, the students' contributions were divided in phases, categorized regarding their references to reasoning or weighting, their use of argumentative resources (see above), and-if identifiable - their explicit function (in the sense of Merciers' argumentative theory [56]), according to the other contributions such as "insisting" or "demanding for further reasoning". In a second phase of analysis, the single steps were summarized and characterized to expanded units that enabled reconstructing the superordinated developmental character of the discussion process.

Table 3. Three examples of individual reasoning and weighting (corresponding to students' writings and markings in boxes 2 and 3 in Figure 1) in the individual Target-Map before (pre) and after (post) group negotiation (weightings: $1=$ not at all important, $4=$ very important); the written statements of examples $B$ and $C$ originate from students who belong to the group negotiation in Table 3.

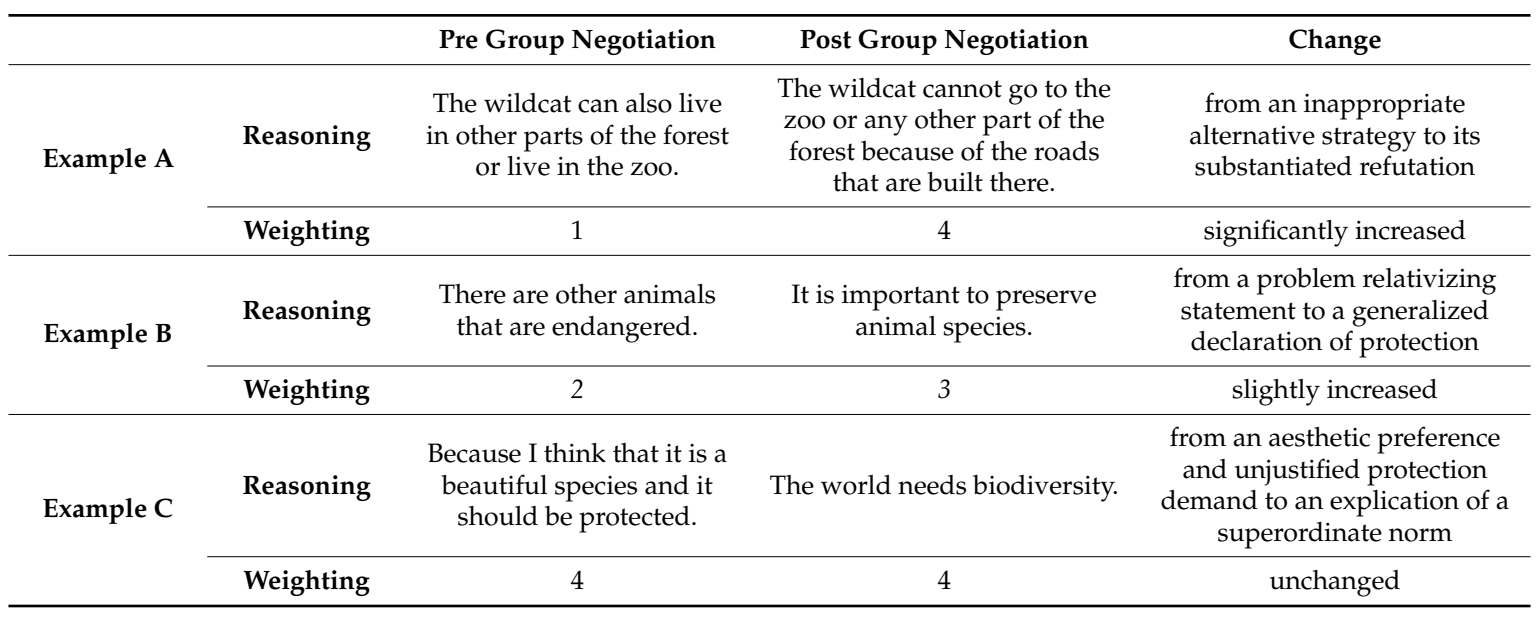


Table 4. Passage of group negotiation about the wildcat protection with a step-by-step and a phased interpretation of the process.

\begin{tabular}{|c|c|c|}
\hline \multirow{2}{*}{ Passage of Group Negotiation Transcript } & \multicolumn{2}{|c|}{ Interpreted Negotiation Process } \\
\hline & Step-by-Step & Developmental Character \\
\hline \multicolumn{3}{|l|}{ S 1: So, rescue of the wildcats } \\
\hline $\begin{array}{l}\text { S 2: Very important! } \\
\text { S 1: Very important! }\end{array}$ & weighting statements & \multirow{2}{*}{$\begin{array}{c}\downarrow \\
\text { divergent statements on the } \\
\text { basis of weighting } \\
\text { becomes obvious }\end{array}$} \\
\hline $\begin{array}{l}\text { S 4: Not very important. Because I think that } \\
\text { other animals are rarer. [ ... ] It's important, } \\
\text { but there are other things to take care of }[\ldots]\end{array}$ & $\begin{array}{l}\text { divergent weighting statements and } \\
\text { reasoning with facts }\end{array}$ & \\
\hline $\begin{array}{l}\text { S 3: It's an animal species. If it no longer exists, } \\
\text { then it no longer exists. }\end{array}$ & reasoning with facts and consequences & \multirow{2}{*}{$\stackrel{\downarrow}{\text { reasoning }}$} \\
\hline $\begin{array}{l}\text { S 4: You have to take care of it, but there are } \\
\text { also more important things. }\end{array}$ & insisting on relativizing objection & \\
\hline $\begin{array}{l}\text { S 3: No! } \\
\text { S 4: Yes, there is! } \\
\text { S 3: No! } \\
\text { S 4: Yes! }\end{array}$ & insisting on statements & $\begin{array}{c}\downarrow \\
\text { the ongoing lack of } \\
\text { consensus becomes obvious }\end{array}$ \\
\hline $\begin{array}{l}\text { S 3: Imagine that at some point they are gone } \\
\text { because somebody said that there are more } \\
\text { important things. } \\
\text { S 2: I think it's very important! } \\
\text { S 1: I would also say very important. }\end{array}$ & $\begin{array}{l}\text { reasoning by strengthen the } \\
\text { consequences and renewed } \\
\text { weighting statement }\end{array}$ & $\begin{array}{l}\downarrow \\
\text { expanded reasoning }\end{array}$ \\
\hline S 4: No, no, no! & insisting on objection & \multirow{2}{*}{$\begin{array}{c}\downarrow \\
\text { request for reasoning }\end{array}$} \\
\hline S 2: Reason? & demanding for reasoning & \\
\hline $\begin{array}{l}\text { S 3: Otherwise they will die out! } \\
\text { S 4: Bow! } \\
\text { S 3: The world needs biodiversity! } \\
\text { S 2: Exactly! }\end{array}$ & $\begin{array}{l}\text { reasoning with renewed consequences } \\
\text { and the corresponding norm }\end{array}$ & $\stackrel{\downarrow}{\downarrow}$ further expanded reasoning \\
\hline S 4: Others die out, too! & reasoning with relativizing facts & \\
\hline S 3: Not if you protect them. & $\begin{array}{l}\text { insisting on protection as the } \\
\text { problem's solution }\end{array}$ & \\
\hline
\end{tabular}

During the intervention, according to the concept shown in Table 2, the students examined the problem using the given information material and developed arguments, which were reduced to four pro- and counter-arguments through group negotiation. Then, students completed their individual Target-Mats before participating in the group process of justification and weighting using these Target-Mats. After the group process, the students received their initial individual Target-Mat again in order to be able to make any relevant changes in the weighting and justifications. Table 3 shows three exemplary details of individual Target-Mats, all of which refer to the argument of the wildcat protection. These examples give first insights into the potential of correspondingly initiated negotiation processes that are used to fulfill the particularly relevant criteria of reason and critical reflection (as previously discussed).

Example A shows an alternative strategy frequently identified at this stage, in which the students try to avoid the negative consequences criticized in the argument (i.e., other habitat for wildcats). However, this proposal is not objectively acceptable because of limited forest areas and the importance of large, non-fragmented areas. The revision carried out in the post-phase refers to this fragmentation problem, and demonstrates a fundamental change of position through fact-driven correction. The authentic character of this development is additionally underlined by the congruent increase of the weighting using a range from 1 to 4 anchors of scale. This revision of justification and weighting based on facts is of particular importance, because the facts on fragmentation were already known before the Target-Mat was used in the pre-phase. Thus, this case exemplifies the potential of group-based negotiations to raise awareness of relevant facts, which is one of the most important goals of the SSI argumentation [1]. 
The student who wrote the argument (see example B) begins with a problem-relativizing statement before the group negotiation occurs, and cites the endangered status of other species. This reference to the endangered status of other species can be classified as non-functional [59], because the need to protect other species does not diminish the relevance of the present claim for wildcat protection. The statement after the negotiation process shows a useful change that abandons the approach of non-functional relativistic reasoning and becomes a generalized protection statement accompanied by a plausible increase of the weighting. Although this statement of general protection does not meet the formal argumentation criteria and does not contain an improved justification, the change indicates a significant development in the student's thinking. This gives an impression of the potential of group negotiation to reduce non-functional reasoning strategies and bring more convincing reasons to the fore.

Example $\mathrm{C}$ shows an even greater change from an aesthetic preference to the explicit naming of biodiversity as a superordinate norm. Against the background of many argumentation models $[59,60]$, this would be classified as an increase in the quality of argumentation. This is because an explicit reference to norms both formally and in the sense of its communicative persuasiveness is classified as more functional than an initially aesthetic reference. This is of particular interest because the student does not change his or her weighting. There was no reason to change the justification by changing the weighting; therefore, this suggests that only the recognition of the limited carrying capacity of aesthetic preferences has led to this change. This underlines the potential of the negotiation processes to activate critical thinking and to initiate corresponding revision processes.

This example describing a transformation from aesthetic interest to a norm or value orientation can also be discussed on a more general level. Access to evaluation questions is usually initially based on intuitive preferences, which have been widely discussed as a general limitation of humans' rational capacities [61]. Irrespective of this critical view, the negotiation of common norms and values remains an essential element of political opinion forming. However, access to normative dimensions that have a greater potential for consensus building is often not available to students with little experience of negotiating socially relevant problems. They need the opportunity and time to discover, while negotiating, which approaches convince others and which do not. According to our interpretations, the effects of these experiences become apparent after negotiations with the Target-Mat, which explains the change from an aesthetic interest to an explicit superordinate norm. Therefore, we assume that semi-structured negotiation processes have the potential to activate individual connections to the topic (such as aesthetic or other preferences [58] and to initiate the transformation from individual interests to commonly shared norms.

However, the potential previously described has to be critically reflected upon as well. For example, the naming of the superordinate norm in the post-phase could have been made without deeper convictions or justifications, because the formulation "The world needs biodiversity" (Table 3, Example B, Post-Phase Supplement) gives no indication of its deeper consideration or developmental origin.

For further insights, not into the individual depth of justification but into the previous group process, Table 4 presents an analysis of a corresponding group negotiation (including the two students from examples $\mathrm{B}$ and $\mathrm{C}$ in Table 3) for the weighting and justification of the argument of wildcat protection. By categorizing the single steps of the negotiation process with regard to their argumentative and discursive character, and by the further identification of general process phases, it becomes clear that different weightings repeatedly initiate phases of reasoning (see Table 4, column "phased"). Therefore, the link between argument-related reasoning and weightings offers a simple access to the divergent positions functioning as a concrete invitation to argue.

This motivating character becomes more evident at a step-by-step-level of analysis (with classification according to the criteria discussed above): When student 4 still insists on his objection (freedom) after the expanded argumentation by the others (students 2 and 3), student 2 directly asks for reasons (consensus). This dynamic shows that the weightings offer the possibility of identifying 
diverging positions without elaborate argumentation during the first step (equality), but leads to the necessity of subsequent reasoning (reason). Although there is no explicit critical reflection at this stage, the student's request for argumentation needed an earlier reflection on the opponent's quality of argumentation. This indirectly reveals elements of critical reflection and the resulting regulation of the negotiation process. Thus, the lack of instruction on the quality of reasoning within the Target-Mat gives students the freedom to recognize when deeper reasoning is necessary.

The self-developed awareness for necessary argumentation leads to a remarkable development of argumentation from a simple statement of relevance to the concretization of the species' character. This is accompanied by the realization of irreversible consequences up to the final statement of a general protection of diversity as a superordinate norm. Thus, the criterion reason, with its particular relevance for the whole approach, is met in a remarkable way. High-ranking argumentative elements such as actual facts and consequences [2] as well as norms [16] become relevant for the students within the process, although the process starts at a low threshold with weighting statements ensuring a broad participation.

\section{Conclusions}

Due to the underdetermined nature of the sustainability concept, it can be seen that one essential challenge of transformation lies in social discursive negotiation processes. These are necessary in order to be able to reach consensus on future developments [16] and to correspondingly stabilize sustainability norms [24]. In addition, the increasing fragmentation of society into different communities of interest with decreasing opportunities for communicative-discursive exchange seems to be enforced by the virtual sphere of digital media [62] (p. 162). Therefore, the context of formal education offers an important and valuable space for pupils to experience initiating negotiation processes across social boundaries and to make clear the differences between possible roles (i.e., deliberating citizen versus consumer).

This also calls for a political turn in sustainability education in terms of deliberation and negotiation. In the sense of an orientation toward the deliberative democracy approach, in connection with a modern view of human argumentation as cooperative social practice [56], an instructional approach is presented that aims at an activating discourse orientation, but does not standardize argumentation or process structures, because it offers statements as contrast sets and process structures as negotiable.

In addition to the theoretical justification and proposals for instruction and exemplary case analysis that have been conducted and described in this paper, it must be shown that corresponding settings initiate in-depth negotiation processes with authentic individual involvement. Furthermore, evidence is necessary that experiences of self-efficacy in the situated settings will take place, and that they will increase the individuals' willingness to participate in discursive negotiation processes on sustainability issues. It also involves their ability to acknowledge the characteristics of such a resource and time-consuming activity as of being central relevance in democratic societies. We assume that this could be accompanied by a lessening of the simplifying cut-off strategies of evaluation in the face of complex sustainability problems. In particular, the initiation of in-depth argumentation with a reduction of simple preference statements and a strengthening of factual and normative references has already been demonstrated in the context of an intervention study (see [58]).

Looking back at our initial considerations on the difficulties in defining sustainability, Ramsey emphasizes aptly: "For a definition to make sense, the social practices of interpreting have to be in place already" [23] (p. 1085). In this sense, the here-presented discourse-based approach for sustainability decision making aims at implementing a social practice that allows to clarify and stabilize the relevant normative foundations for a more sustainable future.

Author Contributions: Both authors contribute substantially to the text. They both developed the theoretical framework, analyzed the intervention examples and wrote the text.

Funding: This research received no external funding. 
Acknowledgments: The authors thank Janet MacLaughlin (University of Hildesheim) for the detailed proof-reading of the text).

Conflicts of Interest: The authors declare no conflict of interest.

\section{References}

1. Sadler, T.D.; Zeidler, D.L. Patterns of Informal Reasoning in the Context of Socioscientific Decision Making. J. Res. Sci. Teach. 2005, 42, 112-138. [CrossRef]

2. Grace, M. Developing high quality decision-making discussions about biological conservation in a normal classroom setting. Int. J. Sci. Educ. 2009, 31, 551-570. [CrossRef]

3. Bybee, R. Achieving Scientific Literacy; Heinemann: Portsmouth, UK, 1997; ISBN 978-043-507-134-9.

4. Kolstø, S.D. Scientific Literacy for Citizenship: Tools for Dealing with the Science Dimension of Controversial Socioscientific Issues. Sci. Educ. 2001, 85, 291-310. [CrossRef]

5. Sadler, T.D. Informal reasoning regarding socio-scientific issues: A critical review of research. J. Res. Sci. Teach. 2004, 41, 513-536. [CrossRef]

6. Nielsen, J.A. Science in discussions: An analysis of the use of science content in socioscientific discussions. Sci. Educ. 2012, 96, 428-456. [CrossRef]

7. Seethaler, S.; Linn, M. Genetically modified food in perspective: An inquiry-based curriculum to help middle school students make sense of tradeoffs. Int. J. Sci. Educ. 2004, 26, 1765-1785. [CrossRef]

8. Arvai, J.L.; Campbell, V.E.A.; Baird, A.; Rivers, L. Teaching students to make better decisions about the environment: Lessons from the decision sciences. J. Environ. Educ. 2004, 36, 33-44. [CrossRef]

9. De Haan, G. Bildung für nachhaltige Entwicklung-Ein neues Lern- und Handlungsfeld. Unesco Heute 2006, $53,4-8$.

10. De Haan, G. The development of ESD-related competencies in supportive institutional frameworks. Int. Rev. Educ. 2010, 56, 315-328. [CrossRef]

11. Bögeholz, S.; Böhm, M.; Eggert, S.; Barkmann, J. Education for Sustainable Development in German Science Education: Past-Present-Future. Eurasia J. Math. Sci. Technol. Educ. 2014, 10, 231-248. [CrossRef]

12. Eggert, S.; Bögeholz, S. Göttinger Modell der Bewertungskompetenz-Teilkompetenz “Bewerten, Entscheiden und Reflektieren“ für Gestaltungsaufgaben Nachhaltiger Entwicklung. Z. Didakt. Nat. 2006, 12, 177-197.

13. Wals, A.E.J.; Jickling, B. Sustainability in higher education: From doublethink and newspeak to critical thinking and meaningful learning. Int. J. Sustain. High. Educ. 2002, 15, 221-232. [CrossRef]

14. Böttcher, F.; Meisert, A. Effects of Direct and Indirect Instruction on Fostering Decision-Making Competence in Socioscientific Issues. Res. Sci. Educ. 2013, 43, 479-506. [CrossRef]

15. Kuhn, D. A role for reasoning in a dialogic approach to critical thinking. Topoi 2018, 37, 121-128. [CrossRef]

16. Ratner, B.D. "Sustainability" as a Dialogue of Values: Challenges to the Sociology of Development. Sociol. Inq. 2004, 74, 50-69. [CrossRef]

17. Ciegis, R.; Ramanauskiene, J.; Martinkus, B. The Concept of Sustainable Development and its Use for Sustainability Scenarios. Eng. Econ. 2009, 62, 28-37.

18. WCED-Brundtland Commission. Report of the World Commission on Environment and Development: Our Common Future; Oxford University Press: Oxford, UK, 1987.

19. Koll-Schretzenmayr, M. Was kommt nach der Nachhaltigkeit? (What comes after sustainability?). DisP 2007, $43,3-4$.

20. Vos, R.O. Defining sustainability: A conceptual orientation. J. Chem. Technol. Biotechnol. 2007, 82, 334-339. [CrossRef]

21. Unmüßig, B.; Sachs, W.; Fatheuer, T. Kritik der Grünen Ökonomie; Oekom: München, Germany, 2015; ISBN 978-386-581-748-8.

22. Dingler, J. Postmoderne und Nachhaltigkeit; Oekom: München, Germany, 2003; ISBN 978-393-658-126-3.

23. Ramsey, J.L. On not Defining Sustainability. J. Agric. Environ. Ethics 2015, 28, 1075-1087. [CrossRef]

24. Deitelhoff, N.; Zimmermann, L. Things We Lost in the Fire: How Different Types of Contestation Affect the Robustness of International Norms. International Studies Review 2018, viy080, 1-26. [CrossRef]

25. Waas, T.; Hugé, J.; Block, T.; Wright, T.; Benitez-Capistros, F.; Verbruggen, A. Sustainability Assessment and Indicators: Tools in a Decision-Making Strategy for Sustainable Development. Sustainability 2014, 6, 5512-5534. [CrossRef] 
26. Kumar, A.; Sah, B.; Singh, A.R.; Deng, Y.; He, X.; Kumar, P.; Bansal, R.C. A review of multi criteria decision making (MCDM) towards sustainable renewable energy development. Renew. Sustain. Energy Rev. 2017, 69, 596-609. [CrossRef]

27. Bengtsson, S.L.; Östman, L.O. Globalisation and education for sustainable development: Emancipation from context and meaning. Environ. Educ. Res. 2013, 19, 477-498. [CrossRef]

28. Burmeister, M.; Rauch, F.; Eilks, I. Education for Sustainable Development (EFS) and chemistry education. Chem. Educ. Res. Pract. 2012, 13, 59-68. [CrossRef]

29. Vucetich, J.A.; Nelson, M.P. Sustainability: Virtuous or Vulgar? BioScience 2010, 60, 539-544. [CrossRef]

30. Habermas, J. Drei normative Modelle der Demokratie: Zum Begriff deliberativer Demokratie. In Die Chancen der Freiheit. Grundprobleme der Demokratie; Münkler, H., Ed.; Piper: München, Germany, 1992; pp. 11-24, ISBN 978-349-211-545-2.

31. Apel, K.-O. Diskurs und Verantwortung: Das Problem des Übergangs zur Postkonventionellen Moral; Suhrkamp: Frankfurt am Main, Germany, 1990; ISBN 978-351-857-924-4.

32. Fishkin, J.S. When the People Speak: Deliberative Democracy and Public Consultation; University Press: Oxford, UK, 2011; ISBN 978-019-960-443-2.

33. Cohen, J. Deliberative Democracy and Democratic Legitimacy. In The Good Polity; Hamlin, A., Pettit, P., Eds.; Blackwell: Oxford, UK, 1991; pp. 17-34, ISBN 978-0631180883.

34. Gutmann, A.; Thompson, D. Democracy and Disagreement; The Belknap Press of Harvard University Press: Cambridge, UK, 1998; ISBN 978-067-419-766-4.

35. Pettit, P. Deliberative Democracy, the Discursive Dilemma, and Republican Theory. In Debating Deliberative Democracy; Fishkin, J.S., Laslett, P., Eds.; Blackwell: Oxford, UK, 2003; pp. 138-163, ISBN 978-140-510-043-4.

36. Della Porta, D. Can Democracy Be Saved? Polity Press: Cambridge, UK, 2013; ISBN 978-074-566-459-0.

37. Chappell, Z. Deliberative Democracy; Palgrave Macmillan: Hampshire, UK, 2012; ISBN 978-023-025-215-8.

38. Samuelsson, M.; Bøyum, S. Education for deliberative democracy: Mapping the field. Utbild. Demokr. 2015, 24, 75-94.

39. Kuhn, D. Metacognitive Development. Curr. Dir. Psychol. Sci. 2000, 9, 178-181. [CrossRef]

40. Gutmann, A.; Thompson, D. Deliberative Democracy Beyond Process. J. Political Philosp. 2002, 10, $153-174$. [CrossRef]

41. Munnichs, G. Rational Politics? An Exploration of the Fruitfulness of the Discursive Concept of Democracy. In Discourse and Democracy; Schomberg, R., Baynes, K., Eds.; State University of York Press: Albany, NY, USA, 2002; ISBN 978-079-145-498-5.

42. Lodge, M.; Wegrich, K. The Rationality Paradox of Nudge: Rational Tools of Government in a World of Bounded Rationality. Law Policy 2016, 38, 250-267. [CrossRef]

43. Sunstein, C.R. Nudging: A Very Short Guide. J. Consum. Policy 2014, 37, 583-588. [CrossRef]

44. Hansen, P.G.; Jespersen, A.M. Nudge and the Manipulation of Choice. Eur. J. Risk Regul. 2013, 4, 3-28. [CrossRef]

45. Felsen, G.; Castelo, N.; Reiner, P. Decisional enhancement and autonomy: Public attitudes towards overt and covert nudges. Judgm. Decis. Mak. 2013, 8, 202-213.

46. Grace, M.; Byrne, J. Engaging pupils in decision-making about biodiversity conservation issues. Sch. Sci. Rev. 2010, 91, 73-80.

47. Gresch, H.; Hasselhorn, M.; Bögeholz, S. Training in decision-making strategies: An approach to enhance students' competence to deal with socioscientific issues. Int. J. Sci. Educ. 2013, 35, 2587-2607. [CrossRef]

48. Cohen, J. Procedure and substance in deliberative democracy. In Deliberative Democracy: Essays on Reason and Politics; Bohman, J., Rehg, W., Eds.; MIT Press: Cambridge, UK, 1997; pp. 407-438, ISBN 978-026-202-434-1.

49. Enslin, P.; Pendlebury, S.; Tjiattas, M. Deliberative Democracy, Diversity and the Challenges of Citizenship Education. J. Philos. Educ. 2001, 35, 115-130. [CrossRef]

50. Panadero, E.; Jonsson, A. The use of scoring rubrics for formative assessment purposes revisited: A review. Educ. Res. Rev. 2013, 9, 129-144. [CrossRef]

51. Feierabend, T.; Eilks, I. Raising Students' Perception of the Relevance of Science Teaching and Promoting Communication and Evaluation Capabilities Using Authentic and Controversial Socio-Scientific Issues in the Framework of Climate Change. Sci. Educ. Int. 2010, 21, 176-196.

52. Ratcliffe, M.; Grace, M. Science Education for Citizenship: Teaching Socio-Scientific Issues; Open University Press: Maidenhead, UK, 2003; ISBN 978-033-522-754-9. 
53. Meisert, A. Bewerten. (decision-making). In Biologiedidaktik; Spörhase, U., Ed.; Cornelsen: Berlin, Germany, 2012; pp. 225-240. ISBN 978-358-923-204-8.

54. Böttcher, F.; Hackmann, A.; Meisert, A. Argumente entwickeln, prüfen und gewichten—Bewertungskompetenz im Biologieunterricht kontextübergreifend fördern (developing, justifying and weighting arguments—Promoting decision-making competence in biology teaching across all contexts). MNU J. 2016, 69, 150-157.

55. Meisert, A. Mit der Zielmat bewerten (use a target mat to evaluate). In Biologie Methodik; Spörhase, U., Ruppert, W., Eds.; Cornelsen: Berlin, Germany, 2018; pp. 236-240, ISBN 978-358-915-442-5.

56. Mercier, H. The argumentative theory: Predictions and empirical evidence. Trends Cogn. Sci. 2016, 20, 689-700. [CrossRef]

57. Michaelis, S.; O'Connor, C.; Resnick, L.B. Deliberative Discourse Idealized and Realized: Accountable Talk in the Classroom and in Civic Life. Stud. Philos. Educ. 2008, 27, 283-297. [CrossRef]

58. Jafari, M.; Meisert, A. Activating Students' Argumentative Resources on Socioscientific Issues by Indirectly Instructed Reasoning and Negotiation Processes. 2019. Available online: https://link.springer.com/article/10. 1007/s11165-019-09869-x\#citeas (accessed on 23 October 2019).

59. Kuhn, D.; Shaw, V.; Felton, M. Effects of Dyadic Interaction on Argumentative Reasoning. Cogn. Instr. 1997, 15, 287-315. [CrossRef]

60. Toulmin, S. The Uses of Argument; Cambridge University Press: Cambridge, UK, 2003; ISBN 978-0521534833.

61. Haidt, J. The emotinal dog and ist rational tail: A social intuitionist approach to moral judgment. Psychol. Rev. 2001, 108, 814-834. [CrossRef] [PubMed]

62. Habermas, J. Ach, Europa; Suhrkamp: Frankfurt am Main, Germany, 2008; ISBN 978-351-812-551-9.

(C) 2019 by the authors. Licensee MDPI, Basel, Switzerland. This article is an open access article distributed under the terms and conditions of the Creative Commons Attribution (CC BY) license (http://creativecommons.org/licenses/by/4.0/). 